\title{
Noninvasive Assessment of Cardiac Index with Transesophageal Echocardiography in Patients Undergoing Mitral Valve Replacement: A Comparison between Determinations at the Mitral Valve and the Ascending Aorta
}

\author{
Xiaoju Hu, Hongwei Shi", Jinyan Yan, Yali Ge, Haiyan Wei \\ Department of Anesthesiology, Nanjing First Hospital, Nanjing Medical University, Nanjing, China. \\ Email: *mdshw@163.com \\ Received February $22^{\text {nd }}, 2013$; revised March $26^{\text {th }}, 2012$; accepted May $17^{\text {th }}, 2013$ \\ Copyright (C) 2013 Xiaoju Hu et al. This is an open access article distributed under the Creative Commons Attribution License, which \\ permits unrestricted use, distribution, and reproduction in any medium, provided the original work is properly cited.
}

\begin{abstract}
Methods: Sixteen patients with American Society of Anesthesiologists status (ASA) II-III, age $\leq 70 \mathrm{yr}$, male or female, preoperatively NYHA II-III and EF $\geq 45 \%$, scheduled for mitral valve replacement (MVR) were studied. Complete intravenous general anesthesia was used for induction and anesthesia maintenance. After anesthesia induction we put the TEE probe into the esophagus. The cardiac index was determined at three periods following MVR: T1 30 minutes later following cessation of bypass, T2 60 minutes after cessation of bypass, T3 90 minutes after cessation of bypass. Statistical analysis was made with the Bland and Altman method. Results: Ninety-six measurements were compared. The cardiac index values at the level of prosthesis mitral valve $\left(\mathrm{CI}_{\mathrm{MV}}\right.$ ) ranged from 1.3 to $5.5 \mathrm{~L} \cdot \mathrm{min}^{-1} \cdot \mathrm{m}^{-2}$ (mean $2.6 \pm$ $0.9)$. The Values of cardiac index at aortic valve $\left(\mathrm{CI}_{\mathrm{AA}}\right)$ ranged from 2.7 to $8.8 \mathrm{~L} \cdot \mathrm{min}^{-1} \cdot \mathrm{m}^{-2}$ (mean $\left.4.9 \pm 1.7\right)$. Bias was $-2.3 \mathrm{~L} \cdot \mathrm{min}^{-1} \cdot \mathrm{m}^{-2}$ and limits of agreement -5.6 to $1.0 \mathrm{~L} \cdot \mathrm{min}^{-1} \cdot \mathrm{m}^{-2}$. Conclusion: During mitral valve replacement, doubtful correlations were observed between values of cardiac index at the mitral valve and the ascending aorta using TEE.
\end{abstract}

Keywords: Cardiac Index; Cardiac Output; Transesophageal Echocardiography; Mitral Valve Replacement; Ascending Aorta

\section{Introduction}

Quantification of cardiac index (CI), an elementary variable of cardiovascular function, is essential for adequate prognostic evaluation especially in cardiac surgery. Use of the pulmonary artery catheter (PAC) to determine CI is considered as the gold standard. However, some reports indicate that significant complications are often associated with $P A C$, including catheter-associated bloodstream infection, arrhythmias, pneumothorax, and venous thrombosis [1,2]. And because of the national conditions, the patients in every cardiac surgery all used the PAC don't come true in China. However, in the past decade, transesophageal echocardiography (TEE) has been proposed as a noninvasive, independently operated and cost-

\footnotetext{
"Corresponding author.
}

effective method for CI measurement in cardiac surgery; and increasingly accepted in open cardiac operation [3]. The satisfactory correlation between cardiac output measurement with TEE $\left(\mathrm{CO}_{\mathrm{TEE}}\right)$ and thermodilution via a pulmonary artery catheter $\left(\mathrm{CO}_{\mathrm{PAC}}\right)$ has been investigated [4].

Cardiac output $(\mathrm{CO})$ measured at the site of the ascending aorta (AA) using TEE is one of the most frequently used measurements. Cardiac index determined at the ascending aorta $\left(\mathrm{CI}_{\mathrm{AA}}\right)$ is computed as the product of the velocity time integral $\left(\mathrm{VTI}_{\mathrm{AA}}\right)$ and the cross sectional area of the ascending aorta $\left(\mathrm{CSA}_{\mathrm{AA}}\right)$ and the heart rate, divided by the body surface area of the patient, according to the formulas in Table 1 formulas 1 - 3. However, according to the formula1 in Table 1, a common source of inaccuracy, when calculating the $\mathrm{CI}$, derived from the 
square of the diameter (Table 1 formula1). After MVR, the mitral annular area is known by the specifications from the manufacturer. Therefore one only need to measure the VTI of the mitral valve (MV) to determine the stroke volume and thus the cardiac output and cardiac index $\left(\mathrm{CI}_{\mathrm{MV}}\right)$, according to the formulas 2 - 4 in Table 1. Without the squared diameter that it is the source of the greatest error, the method for $\mathrm{CI}_{\mathrm{MV}}$ measurement should be more accurate, since the MV area has been already known. Considering these given above, it would be helpful to compare $\mathrm{CI}_{\mathrm{AA}}$ to $\mathrm{CI}_{\mathrm{MV}}$ determined by TEE. And the good agreement between measurements determined with $\mathrm{CO}_{\mathrm{PAC}}$ and $\mathrm{CO}_{\mathrm{TEE}}$ has been proved [4]. This supplies an alternative method for intraoperative measurement of CI, allowing the comparison of measurements derived from the ascending aorta and mitral valve via TEE with this validated method, when sometimes $\mathrm{CI}_{\mathrm{AA}}$ used TEE can't be obtained accurately.

The objective of the present study was to compare the CI_obtained at the level of the prosthetic mitral valve $\left(\mathrm{CI}_{\mathrm{MV}}\right)$ with the cardiac index thru the ascending aorta $\left(\mathrm{CI}_{\mathrm{AA}}\right)$ in patients undergoing MVR.

\section{Material and Methods}

\subsection{Study Patients}

After institutional ethics committee approval (Nanjing First Hospital, Nanjing Medical University, Nanjing, China), written previous informed consent was obtained from sixteen patients scheduled for mitral valve replacement with cardiopulmonary bypass (CPB). Eligibility criteria included: 1) ASA physical status II -III, preoperative NYHA status II-III; 2) absence of history or symptoms suggestive of cardiovascular, renal, respiratory or systemic disease; 3) normal physical examination results, including normal blood pressure; and 4) normal findings on chest X-ray film, electrocardiographic, Doppler echocardiographic study and routine blood test. Exclusion criteria included: 1) the left ventricular outflow tract abnormality, or ascending aorta stenosis; 2) preoperative ejection fraction less than $45 \%$; 3) presence of

Table 1. Formulas needed in the text.

\begin{tabular}{cc}
\hline & Formula \\
\hline Formula 1 & $\mathrm{CSA}=\pi \times(\mathrm{D} / 2)^{2}$ \\
Formula 2 & $\mathrm{SV}=\mathrm{CSA} \times \mathrm{VTI}$ \\
Formula 3 & $\mathrm{CO}=\mathrm{SV} \times \mathrm{HR}$ \\
Formula 4 & $\mathrm{CI}=\mathrm{CO} / \mathrm{BSA}$ \\
\hline
\end{tabular}

${ }^{*} \mathrm{CSA}=$ cross-sectional area, $\mathrm{D}=$ the diameter of the averaged in three cardiac cycles, $\mathrm{SV}=$ stroke volume, $\mathrm{VTI}=$ velocity time integral, $\mathrm{CO}=$ the cardiac output, $\mathrm{HR}=$ heart rate, $\mathrm{CI}=$ cardiac index, $\mathrm{BSA}=$ body surface area. known risk factors for coronary artery disease; 4) recent illness; 5) pathologic obesity; and 6) preoperative use of cardiotonic agents (such as dopamine, milrinone, phenylephrine, adrenaline, noradrenaline). Thus, 16 patients without contraindication for the use of TEE (4 men, 12 women; mean age $51.9 \pm 15.9$ years, range 18 to 70 ; mean weight $57.0 \pm 7.1 \mathrm{~kg}$, range $46-72 \mathrm{~kg}$; Height $159.6 \pm 7.6 \mathrm{~cm}$, range 151 to 175 ) were studied.

\subsection{Anesthetic Management}

All patients received an intramuscular injection of $0.1 \mathrm{mg}$ of phenobarbital sodium and $0.3 \mathrm{mg}$ of scopolamine thirty minutes prior to surgery. Anesthesia was induced with midazolam $\left(0.05-0.1 \mathrm{mg} \cdot \mathrm{kg}^{-1}\right)$, propofol $(1.5-2.0$ $\left.\mathrm{mg} \cdot \mathrm{kg}^{-1}\right)$, sufentanil $\left(1 \mu \mathrm{g} \cdot \mathrm{kg}^{-1}\right)$ and rocuronium $(0.6-1$ $\left.\mathrm{mg} \cdot \mathrm{kg}^{-1}\right)$. The trachea was then intubated and ventilation was adjusted to an end-tidal carbon dioxide tension of 30 - $35 \mathrm{mmHg}$. After induction of anesthesia and endotracheal intubation, TEE probe (Siemens CV70 imaging system, Germany) was inserted in the esophagus and a complete TEE examination was conducted. During surgery, anesthesia was maintained with propofol $(4-8$ $\left.\mathrm{mg} \cdot \mathrm{kg}^{-1} \cdot \mathrm{h}^{-1}\right)$, remifentanil $\left(0.2-0.4 \mu \mathrm{g} \cdot \mathrm{kg}^{-1} \cdot \mathrm{min}^{-1}\right)$, cisatracurium besilate $\left(2-3 \mu \mathrm{g} \cdot \mathrm{kg}^{-1} \cdot \mathrm{min}^{-1}\right)$. Before sternotomy and cardiopulmonary bypass and after weaning from cardiopulmonary bypass, supplemental bolus doses of sufentanil $1 \mu \mathrm{g}^{\mathrm{kg}} \mathrm{kg}^{-1}$ were administered to strengthen the analgesia respectively.

\subsection{Monitoring Indicators}

Before anesthesia induction, all patients were received standard monitoring. Monitoring consisted of continuous ECG, noninvasive BP and arterial BP, pulse oximetry, end tidal carbon dioxide, temperature, urine output. After induction of anesthesia a double lumen central line was placed. After bypass, all patients were ventricularly paced to achieve $90 \mathrm{bpm}$. Fluid volume was controlled by an infusion pump to maintain the mean arterial pressure greater than $70 \mathrm{mmHg}$. Left ventricular ejection fraction was equal to or more than $45 \%$. We collected data during three study periods as follows: 1) $30 \mathrm{~min}$ after weaning from bypass (T1); 2) $30 \mathrm{~min}$ after T1 (T2); 3) 30 min after $\mathrm{T} 2$ (T3).

\subsection{Experimental Procedures}

Before TEE probe insertion, a nasogastric tube was used to empty air from the stomach and then removed. Transesophageal two-dimensional and pulsed Doppler echocardiography was performed with available multi-planes trans-esophageal echocardiographic probe (Siemens CV70 imaging system, Germany). TEE probe (4.5 - 6.5 $\mathrm{MHz}$ ) was inserted in the esophagus after induction of 
anesthesia and endotracheal intubation. All determinations were performed by the same certified anesthesiologist with TEE probe.

\subsection{Determination of $\mathbf{C I}_{\mathrm{AA}}$}

The end-diastolic frame was selected at the peak of the $\mathrm{R}$ wave on simultaneous electrocardiogram recording and the end-systolic frame was defined as smallest ventricular dimension during the last half of the $\mathrm{T}$ wave.

By rotating the imaging array to approximately $100^{\circ}$ $120^{\circ}$, the ascending aorta diameter was determined in a midesophageal aortic long-axis view (ME AV LAX) 2 $2.5 \mathrm{~cm}$ distal to the aortic valve to allow the automatic calculation of the cross-sectional area of the ascending aorta $\left(\mathrm{CAS}_{\mathrm{AA}}\right)\left(\mathrm{CAS}=\pi \times(\text { diameter } / 2)^{2}[5]\right.$, where the diameter averaged in three cardiac cycles). Then, by rotating the imaging array to approximately $0^{\circ}-20^{\circ}$, in a deep trans-gastric LAX (TG LAX) view, Doppler aortic velocity time integral $\left(\mathrm{VTI}_{\mathrm{AA}}\right)$ and aortic blood flow velocities were measured by a continuous wave Doppler at $2-2.5 \mathrm{~cm}$ the level of the ascending aorta from aortic valve. Three consecutive velocity wave forms were recorded and the VTI was traced and averaged. We also recorded the mean arterial pressure and the CVP at end expiration for these measurements. Velocity time integral (VTI) is area under the velocity curve: sum of velocities during the ejection time. CI was then calculated according to the formulas 3 and 4 [6] in Table 1.

The TEE transducer was positioned in the level of mid-esophageal two chamber view to record the MV VTI $\left(\mathrm{VTI}_{\mathrm{MV}}\right) 0.5 \mathrm{~cm}$ below the $\mathrm{MV}$ prothesis. The stroke volume was calculated, according to the formula 2 in Table 1. Then, the CI was calculated (Table 1, formulas 3 and 4). All measurements were made three times in rapid succession and the results averaged.

In this research, we attempted to ascertain whether cardiac index values obtained through the prosthetic mitral valve correlated strongly enough with those obtained in the ascending aorta, to consider them interchangeable.

\subsection{Statistical Analysis}

Measurement data were expressed as Mean $\pm \mathrm{SD}(\bar{x} \pm \mathrm{s})$. Differences between $\mathrm{CI}_{\mathrm{MV}}$ and $\mathrm{CI}_{\mathrm{AA}}$ were analyzed by Student's t-test. Bland-Altman analysis [7] was used for evaluation the bias and limits of agreement between $\mathrm{CI}_{\mathrm{MV}}$ and $\mathrm{CI}_{\mathrm{AA}}$. The P-value reported was two-sided and value of less than 0.05 was considered statistically significant. All analyses were performed using the MedCalc statistical software.

\section{Results}

Demographic and surgical characteristics of sixteen pa- tients enrolled are presented in Table 2. All patients were given St. Jude mitral valve Medical Regent prosthesis and the valve type and effective orifice area [8] as follows: 3 patients with 27 type bioprosthesis valve, effecttive orifice area $(2.2 \pm 0.4) \mathrm{cm}^{2} ; 1$ patient with 29 bioprosthesis valve, $(2.8 \pm 0.1) \mathrm{cm}^{2} ; 7$ patients given 27 mechanical prosthesis valve, $(1.7 \pm 0.2) \mathrm{cm}^{2} ; 5$ patients with 29 mechanical prosthesis valve, $(1.8 \pm 0.2) \mathrm{cm}^{2}$. Hemodynamic date at different points are shown in Table 3. In all patients, at three intervals, the values of $\mathrm{CI}_{\mathrm{MV}}$ compared with $\mathrm{CI}_{\mathrm{AA}}$ were much less than $\mathrm{CI}_{\mathrm{AA}}(\mathrm{T} 1: \mathrm{t}=$ $-3.745, \mathrm{p}=0.0008 ; \mathrm{T}_{2}: \mathrm{t}=-4.657, \mathrm{p}=0.0001$ and $\mathrm{T}_{3}: \mathrm{t}=$ $-4.627, \mathrm{p}=0.0001$, respectively). Ninety-six measurements $\left(\mathrm{CI}_{\mathrm{AA}}\right.$ vs $\mathrm{CI}_{\mathrm{MV}} 48$ pairs) were analyzed. Figure 1 shows the Bland-Altman Plot. The measurements of cardiac index between the mitral valve and ascending aorta correlated questionably $(\mathrm{r}=-0.577, \mathrm{p}=0.001)$. The $\mathrm{CI}_{\mathrm{MV}}$ values ranged from $1.3 \mathrm{~L} \cdot \mathrm{min}^{-1} \cdot \mathrm{m}^{-2}$ to 5.5 $\mathrm{L} \cdot \mathrm{min}^{-1} \cdot \mathrm{m}^{-2}$ (mean $2.6 \pm 0.9$ ), whereas the values for $\mathrm{CI}_{\mathrm{AA}}$ ranged from $2.7 \mathrm{~L} \cdot \mathrm{min}^{-1} \cdot \mathrm{m}^{-2}$ to $8.8 \mathrm{~L} \cdot \mathrm{min}^{-1} \cdot \mathrm{m}^{-2}$ (mean $4.9 \pm 1.7$ ). Mean bias was $-2.3 \mathrm{~L} \cdot \mathrm{min}^{-1} \cdot \mathrm{m}^{-2}$. The 95\% limit of agreements between $\mathrm{CI}_{\mathrm{MV}}$ and $\mathrm{CI}_{\mathrm{AA}}$ (Figure 1) were $-5.6 \mathrm{~L} \cdot \mathrm{min}^{-1} \cdot \mathrm{m}^{-2}$ to $1.0 \mathrm{~L} \cdot \mathrm{min}^{-1} \cdot \mathrm{m}^{-2}$.

\section{Discussion}

In our study, the primary findings indicate that the correlation between cardiac index computed by hemodynamic data measured at the level of mitral valve and through the ascending aorta using TEE in patients undergoing mitral valve replacement is questionable. And, due to the mean bias and discrepancies between the data at two different sites, these two sites are not interchangeable.

Table 2. Demographic and clinical characteristics of the patients.

\begin{tabular}{cc}
\hline Parameters & Valve \\
\hline Sex, M/F & $4 / 12$ \\
Age, $\mathrm{yr}$ & $51.9 \pm 15.9$ \\
Weight, $\mathrm{kg}$ & $57.0 \pm 7.1$ \\
Height, $\mathrm{cm}$ & $159.6 \pm 7.6$ \\
Body mass, $\mathrm{m}^{2}$ & $1.6 \pm 0.1$ \\
Ascending aorta diameter, cm & $2.5 \pm 0.4$ \\
Mean cross-sectional area of the aortic artery, $\mathrm{cm}^{2}$ & $4.8 \pm 0.1$ \\
Preoperative EF, \% & $62.0 \pm 5.5$ \\
Aortic cross-clamp time, min & $60.6 \pm 14.4$ \\
Cardiopulmonary bypass time, min & $93.1 \pm 17.3$ \\
Surgery time, hour & $3.6 \pm 0.5$ \\
\hline
\end{tabular}

Values are expressed as Mean $\pm \mathrm{SD}$. 
Table 3. Hemodynamic data at different points in 16 patients.

\begin{tabular}{cccc}
\hline parameters & $\mathrm{T} 1$ & $\mathrm{~T} 2$ & $\mathrm{~T} 3$ \\
\hline $\mathrm{VTI}_{\mathrm{AA}}(\mathrm{cm})$ & $26.6 \pm 8.4$ & $24.0 \pm 5.0$ & $23.5 \pm 6.1$ \\
$\mathrm{VTI}_{\mathrm{MV}}(\mathrm{cm})$ & $18.9 \pm 5.3$ & $19.8 \pm 4.7$ & $18.5 \pm 6.5$ \\
$\mathrm{CI}_{\mathrm{AA}}\left(\mathrm{L} \cdot \mathrm{min}^{-1} \cdot \mathrm{m}^{-2}\right)$ & $4.8 \pm 1.9$ & $4.5 \pm 1.5$ & $4.8 \pm 1.9$ \\
$\mathrm{CI}_{\mathrm{MV}}\left(\mathrm{L} \cdot \mathrm{min}^{-1} \cdot \mathrm{m}^{-2}\right)$ & $2.7 \pm 1.1^{\mathrm{a}}$ & $2.5 \pm 0.8^{\mathrm{a}}$ & $2.5 \pm 0.9^{\mathrm{a}}$ \\
$\mathrm{CVP}(\mathrm{mmHg})$ & $9.1 \pm 3.3$ & $9.6 \pm 3.7$ & $9.2 \pm 3.3$ \\
$\mathrm{MAP}(\mathrm{mmHg})$ & $65.2 \pm 9.2$ & $70.4 \pm 11.2$ & $70.1 \pm 8.6$ \\
$\mathrm{HR}(\mathrm{b} / \mathrm{min})$ & 90 & 90 & 90 \\
\hline
\end{tabular}

All data are expressed as Mean $\pm \mathrm{SD}$. $\mathrm{AP}<0.01$ versus $\mathrm{CI}_{\mathrm{AA}}$.

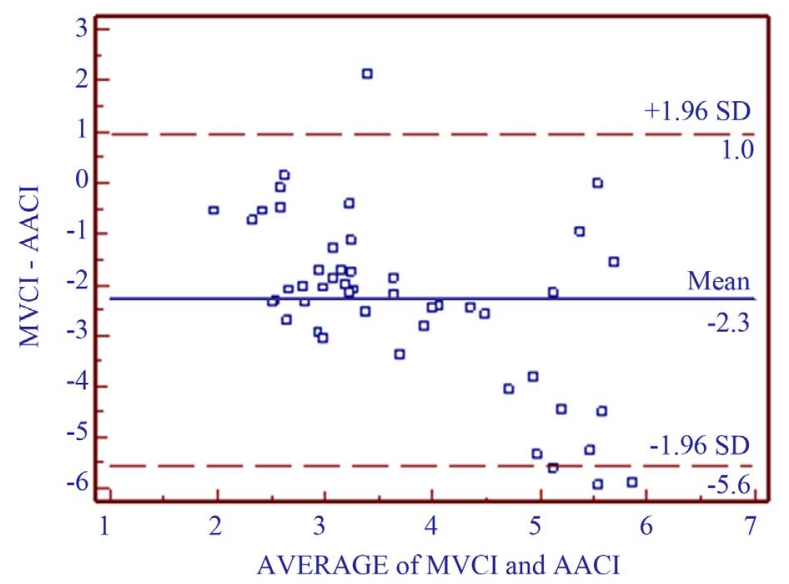

Figure 1. Bland-Altman analysis for repeated measurements plot. $\mathrm{MVCI}=$ cardiac index determination transmittral valve; $\mathrm{AACI}=$ cardiac index determination by ascending aorta. Middle line represents bias (mean difference of $\mathrm{CI}_{\mathrm{MV}}$ and $\mathrm{CI}_{\mathrm{AA}}:-2.3 \mathrm{~L} \cdot \mathrm{min}^{-1} \cdot \mathrm{m}^{-2}$ ); Two outer lines are limits of agreement.

To our knowledge, utilizing the mitral valve for determining $\mathrm{CO}$ and $\mathrm{CI}$ has been sparse due to the inherent inaccuracy in determining the mitral valve cross-sectional area. No doubt this is why there have been many reports utilizing the TEE at the ascending aorta, and the PA thermodilution catheter for $\mathrm{CO}$ determinations. Determining CI via the prosthetic mitral valve, where the area is known, has not been investigated. In contrast, estimation of $\mathrm{CO}$ via TEE from the blood velocity of the mitral valve has been reported [9]. If the $\mathrm{CO}$ has been reported, then determining the $\mathrm{CI}$ is essentially the same. Cabrera Schulmeyer MC [4] et al. reported that the correlation between cardiac output measurement with TEE and thermodilution via a pulmonary artery catheter is satisfactory $(r=0.926)$. In the study, we chose to monitor hemodynamic data using TEE to compare correlation of $\mathrm{CI}_{\mathrm{MV}}$ with $\mathrm{CI}_{\mathrm{AA}}$. And after mitral valve replacement, we found the correlation between them was far from reliability. The prosthetic mitral valve area is provided by the manufacturer, and therefore the error of inaccurate measurements with TEE is avoided. Another comparative study identified that determination of cross-sectional area at the blood volume velocity via TEE leaded to one of the primary measurement errors [10].

Currently, the pulmonary artery catheter is considered the standard approach in determining the $\mathrm{CO}$ and $\mathrm{CI}$. However, it is well recognized that the $\mathrm{CO}$ determined by pulmonary artery thermodilution catheter is less than actual, especially in the presence of tricuspid regurgitation [11]. And thermodilution via pulmonary artery catheter has limitations, some of which are expensive, invasive, source of infection, TR, PAS, left atrial or left ventricular tumor and tetralogy of Fallot. The correlation between $\mathrm{CO}$ measured by thermodilution and using TEE is satisfactory [12]. Furthermore, doppler echocardiography is uniquely suited to evaluate valve function as well as hemodynamics [13]. And the clinical application for TEE use has other advantages. It is visual, economical, widespread clinical, noninvasive monitoring and absent from operative visual field and interference of operative procedure. The main disadvantage to use the TEE is that you would have to repeatedly place the probe every time you wanted to re-evaluate the CI.

When we recorded the velocity tracings, the ultrasound beam and blood flow were sampled 20 degrees or less parallel to one another to increase accuracy of the measurements [14]. The time velocity integral was assessed from the long-axis view of the deep trans-gastric [12]. In addition, interferences of the prosthetic mitral valve and rotation of the heart made some measurements difficult and subject to less accuracy.

Even though the methods of measurement of $\mathrm{CI}_{\mathrm{MV}}$ were similar to the $\mathrm{CI}_{\mathrm{AA}}$ in this study, the results of $\mathrm{CI}$ from two measurements monitoring via a transesophageal echocardiography indicted to be different (mean bias $-2.3 \mathrm{~L} \cdot \mathrm{min}^{-1} \cdot \mathrm{m}^{-2}$ ). There were several possible explanations for these differences. Despite the small influence of the use of PEEP on monitoring CI, likely because the use of PEEP still affected the assessments. Positive end expiratory pressure has been shown to affect cardiac index in a study by Rellahi JL, et al. $[15,16]$ by an amount as much as $19 \%$. We utilized the same amount of PEEP on all patients during our cases.

We obtained the blood volume inflow tract of left ventricular at the level of replaced mitral valve, and ascending aorta. In principle, using the same method of measurement, the stroke volume of the left ventricular inflow tract (i.e. MV) should be equal to the stroke volume in the ascending aorta. However, the mean bias was still to be present. We believe the primary cause was our as- 
sumption that the ascending aortic VTI and diameter were interchangeable with the LVOT and VTI across the aorta valve. Another aspect perhaps was coronary blood flow down the ostia. And the VTI obtained from the maximal blood stream instead of the mean that could not be measured technologically. According to the algorithm applied in calculating $\mathrm{CI}$, the aortic diameter changed the product of $\mathrm{CI}_{\mathrm{AA}}$ in the way of square, and the VTI in the way of multiplication, this resulted in a significant overestimation of the $\mathrm{CI}_{\mathrm{AA}}$. Fortunately, the value $\mathrm{CI}_{\mathrm{MV}}$ was lacking this source of error. Our study has several important limitations. First, there was no comparison with a so-call "gold standard" method for the measurement of cardiac index (as thermodilution using a pulmonary artery catheter (PAC)) in the clinical setting, and despite acceptable inter- and intra-variability for CI with TEE, which method over- and underestimated the true value of CI remains speculative. To reduce these problems all determinations were performed by the same certified anesthesiologist. However, when a good determination of ascending aorta and proper alignment of the ultrasound beam were obtained, there was agreement between $\mathrm{TEE}_{\mathrm{CO}}$ and $\mathrm{CO}_{\mathrm{PAC}}$ [14]. Second, there was lack of synchronization when measured for $\mathrm{CI}_{\mathrm{MV}}$ and $\mathrm{CI}_{\mathrm{AA}}$. Even though when we carefully placed the standard position of the probe and recorded the data in the suggested handling time, the measurements at mitral valve prosthesis may be determined at a time. However, in the left ventricular outflow tract, flow may be affected at another time by widely varying hemodynamic conditions. Third, in our study, the types of mitral valve prostheses were different; in addition, the valve orifice area of the same type from mechanical prosthesis to bio-prosthesis was found significantly variable. Finally, although not evident from the visual inspection of the Bland Altman plot, our result might had been weighted by outlier data because we studied $96 \mathrm{CI}$ measurements coming from 16 patients.

In conclusion, we found the application of TEE for measuring cardiac index and monitoring cardiovascular function is simple, practical and noninvasive, and the correlation of CI between the prosthesis mitral valve and ascending aorta by TEE is questionable $(\mathrm{r}=-0.577, \mathrm{p}=$ 0.001). However, the values of $\mathrm{CI}_{\mathrm{AA}}$ were found to be greater than the values $\mathrm{CI}_{\mathrm{MV}}$ by a significant difference. Nevertheless, together with clinical setting, this data suggests that the two methods for obtaining the cardiac index by TEE are not interchangeable in this setting of mitral valve replacement. Further outcome studies should be performed in patients with specific medical conditions (e.g. same prosthetic type, size, just mitral mechanical valve or mitral bio-valve), in which cardiovascular data derived by TEE are compared with pulmonary artery catheter derived data.

\section{REFERENCES}

[1] E. D. Robin, "The Cult of the Swan-Ganz Catheter: OverUse and Abuse of the Pulmonary Flow Catheters," Annals of Internal Medicine, Vol. 103, No. 3, 1985, pp. 445-449. doi:10.7326/0003-4819-103-3-445

[2] W. C. Shoemaker, "Use and Abuse of the Balloon Tip Pulmonary Artery (Swan-Ganz) Catheter: Are Patients Getting Their Money Worth?" Critical Care Medicine, Vol. 18, No. 11, 1990, pp. 1294-1296. doi:10.1097/00003246-199011000-00025

[3] I. A. Muhiudeen, H. F. Kuecherer, E. Lee et al. "Intraoperative Estimation of Cardiac Output by Transesophageal Pulsed Doppler Echocardiography," Anesthesiology, Vol. 74, No. 1, 1991, pp. 9-14. doi:10.1097/00000542-199101000-00003

[4] M. C. Cabrera Schulmeyer, R. A. Vega Sepulveda and E. G. Santelices, "Cuevas Intraoperative Measurement of Cardiac Output by Transesophageal Echocardiography of Transmitral Flow," Revista Española de Anestesiología y Reanimación, Vol. 51, No. 7, 2004, pp. 367-372.

[5] M. A. Branthwaite and R. D. Pradley, "Measurement of Cardiac Output by Thermal Dilution in Man," Journal of Applied Physiology, Vol. 24, No. 3, 1968, pp. 434-438.

[6] A. J. Coats, "Doppler Ultrasonic Measurement of Cardiac Output: Reproducibility and Validation," European Heart Journal, Vol. 11, No. 1, 1990, pp. 49-61.

doi:10.1093/eurheartj/11.suppl_I.49

[7] J. M. Bland and D. G. Altman, "Measuring Agreement in Method Comparison Studies," Statistical Methods in Medical Research, Vol. 8, No. 2, 1999, pp. 135-160. doi:10.1191/096228099673819272

[8] A. C. Perrino and S. T. Reeves, "A Practical Approach to Transesophageal Echocardiography," 2nd Edtion, Lippincott Williams \& Wilkins Ltd., Philadelphia, 2008, pp. 620-623.

[9] S. J. Goldberg, D. F. Dickinson and N. Wolson "Evaluation of an Elliptical Area Technique for Calculating Mitral Blood Flow by Doppler Echocardiography," British Heart Journal, Vol. 54, No. 1, 1985, pp. 68-75.

doi:10.1136/hrt.54.1.68

[10] R. A. Nishimura, F. A. Miller Jr., M. J. Callahan, et al., "Doppler Echocardiography: Theory, Instrumentation, Technique, and Application," Mayo Clinic Proceedings, Vol. 60, No. 5, 1985, pp. 321-343. doi:10.1016/S0025-6196(12)60540-0

[11] M. Balik, P. Plasil and J. Pazout, "Correlation of Cardiac Output Measurement with Transesophageal Echocardiography and Bolus Termodilution Technique in Patients with Various of Tricuspid Regurgitation," Anaesthesiology Intensive Medicine, Vol. 15, 2004, pp. 204-208.

[12] J. Brodka, L. Tulecki, M. Ciurysek, et al., "Thermodilution Stransesophageal Echocardiography for Cardiac Output Measurements in Patients with Good Left Ventricle Function," Anaesthesiology Intensive Therapy, Vol. 42, No. 1, 2010, pp. 15-18.

[13] R. De simone, R. Lange, A. Tanzeem, et al., "Adjustable Tricuspid Valve Annuloplasty Assisted by Intraoperative 
Transesophageal Color Doppler Echocardiography," American Journal of Cardiology, Vol. 71, No. 11, 1993, pp. 926-931.

[14] C. F. Royse, A. G. Royse, D. W. Blake, et al., "Measurement of Cardiac Output by Transesophageal Echocardiography: A Comparison of Two Doppler Methods with Thermodilution," Anaesth Intensive Care, Vol. 27, No. 6, 1999, pp. 586-590.

[15] J. L. Fellahi, B. Valtier, J. P. Bourdarias, et al., "Does Positive End-Expiratory Pressure Ventilation Improve
Left Ventricular Function? A Comparative Study by Transesophageal Echocardiography in Cardiac and Noncardiac Patients," Chest, Vol. 114, No. 2, 1998, pp. 556-562. doi:10.1378/chest.114.2.556

[16] J. L. Fellahi, V. Caille, C. Charron, et al., "Noninvasive Assessment of Cardiac Index in Healthy Volunteers: A Comparison between Thoracic Impedance Cardiography and Doppler Echocardiography," International Anesthesia Research Society, Vol. 108, No. 5, 2009, pp. 1553 1559. 